Volume 19, Number 58 : March 1967 : Price Five Shillings

\title{
EDITORIAL ADVISORY BOARD
}

\section{A. L. L. Baker, DSc(Eng), MICE, MIStructE}

Professor of Concrete Structures and Technology, University of London, Imperial College of Science and Technology

W. F. Cassie, PhD, MS, FRSE, MICE, MIStructE

Professor of Civil Engineering, University of Newcastle upon Tyne

R. H. Evans, CBE, DSc, DèsSc, PhD, MICE, MIMechE, MIStructE

Professor of Civil Engineering, University of Leeds

T. W. Parker, MSc, PhD, FRIC

Director, The Agrément Board

A. D. Ross, BSc, PhD, FRSE, MICE

Professor of Civil Engineering, University of London, King's College

R. E. Rowe, MA, ScD, AMICE

Director of Research and Development, Cement and Concrete Association

EDITOR AND SECRETARY TO THE BOARD

Anthony E. Brooks, BA

Designed, printed and published four times a year by the Cement and Concrete Association

Editorial Office: Wexham Springs, Slough, Bucks, Telephone: Fulmer 212, Telex: Advicret Slough 84352 


\section{Editorial comment}

THE MAJORITY OF THIS ISSUE is devoted to three papers by Save, Janas and Massonnet. These have arisen out of a discussion between Dr Wood and Professor Massonnet, at the London session of the C.E.B. in September 1965, and are related to points put forward in the Magazine of Concrete Research Special Publication of May 1965, entitled Recent developments in yield-line theory. It was felt necessary to emphasize that yield-line theory is contained within the wider theory of limit analysis, despite certain appearances to the contrary which are suggested in the recent literature. In the three papers published here, the authors present a theory of limit analysis for concrete slabs which includes and improves upon the existing yield-line theory.

Upper and lower bounds to the collapse load have been provided by the theories developed previously, and these require a distinction to be made between the statics and kinematics of the problem. The present papers derive the collapse load itself, and refer to this as the "complete solution". Yield-line theory, being an upper-bound method, over-estimates the collapse load, but this defect has now been removed by considering more general collapse mechanisms than those commonly used, and associating them with statically admissible stress fields. This gives complete solutions. In order to extend the theory still further, for example by making it possible to consider membrane action, kinematic admissibility is examined in general terms. The authors feel that the kinematic approach of limit analysis is identical with yield-line theory, for a certain class of mechanisms, and also that it is a wider and better founded theory.

Wood has suggested that limit analysis may not be able to provide coincidental upper- and lower-bound solutions for certain slab problems. Save, however, presents a limit analysis theory in such a way as to include the recent work. The yield criterion is defined in terms of bending moments and, as a result, the associated torque can be found. Some authors include a statement on torque as part of the yield criterion, and thus restrict the range of orientations which can be considered for the section at which yield occurs. Save's approach avoids this restriction and, in this, he is in agreement with Wood's "normal moment criterion", in which a given plastic moment is allowed "to appear at any orientation in plan, ...; this is the criterion which has really prevailed within yield-line theory". Save's presentation would appear to provide an analytical method of handling such an unrestricted orientation of yield moment. He also discusses the conditions under which a mechanism with intersecting yield lines could possess a corresponding statically admissible moment field. These conditions are used in the examples worked out in Massonnet's paper, where complete solutions are derived.

Janas investigates kinematic compatibility conditions, in connexion with upper-bound solutions. Considering a least upper-bound solution, he mentions, as does Save, that certain stress states cannot be satisfied by a yield-line pattern; hence an exact solution for the collapse load sometimes cannot be provided by yield lines. Also, whilst agreeing with Wood's implication that there may be boundary conditions for which yield-line collapse mechanisms cannot be exact solutions, he puts the view that one cannot deny, in general, the existence of coincidental statically and kinematically admissible fields. Janas develops expressions for fans and polygonal slabs, and discusses membrane action.

Massonnet analyses the limit load state of a slab, and derives expressions for the collapse load. He also develops criteria for the admissibility of yield-line patterns and moment fields, and applies these to polygonal slabs simply supported at their edges, and uniformly loaded. Further complete solutions are found for slabs whose yield-line pattern is a combination of fans and rigid elements. For simply supported slabs, several complete solutions are given which, until now, were only upper-bound solutions, but have been improved to give the collapse load and the distribution of moments and support reactions. This facilitates design of the slab and supporting beams. The analysis can be performed without introducing the concept of nodal force. Thus a drawback of yield-line theory has been overcome in that the collapse load is not overestimated and information is available on the field of moments and support reactions at collapse. 